\title{
Implementing Two-Way Dual-Language Immersion Programs Classroom Insights from an Urban District
}

$\mathrm{D}$ ual-language immersion programs - in which students learn core subjects (language arts, math, science, and social studies) in both English and a "partner" language-have been gaining in popularity across the United States. Such programs may use a two-way model, in which roughly half the students are native speakers of the partner language and the other half are native speakers of English, or a one-way model, in which most students are native speakers of a single language. The growing demand for these programs is due in part to studies that have linked dual-language immersion to academic and cognitive benefits for students, regardless of their native language or socioeconomic status. Based on these findings, many educators and policymakers see dual-language immersion, and particularly two-way programs, as a promising way to close achievement gaps and foster academic success for English learners and other disadvantaged students.

As two-way dual-language immersion programs proliferate, the question of how and how well these programs are implemented will take on greater significance. The fidelity of implementation - whether a program is implemented according to its original design-may play an important role in the success of these programs.

The Portland Public School District in Oregon has offered dual-language immersion programs since 1986. To understand how such programs are implemented in classrooms, the RAND Corporation and the American Councils for International Education partnered with the district to observe teachers and students in a subset of Portland's twoway and one-way immersion classrooms. The observations were undertaken as part of a four-year study funded by the U.S. Department of Education's Institute of Education Sciences to assess the causal impact of dual-language immersion programs on students' academic achievement.

The observation data discussed here were collected from the district's two-way programs in Spanish and Russian in spring 2013 and spring 2014. Data collection focused on two important aspects of fidelity of implementation: the extent to which teachers used the instructional practices recommended by the district (i.e., quality of delivery) and the extent to which teachers and students spoke or wrote in the partner language during class periods designed to be conducted in

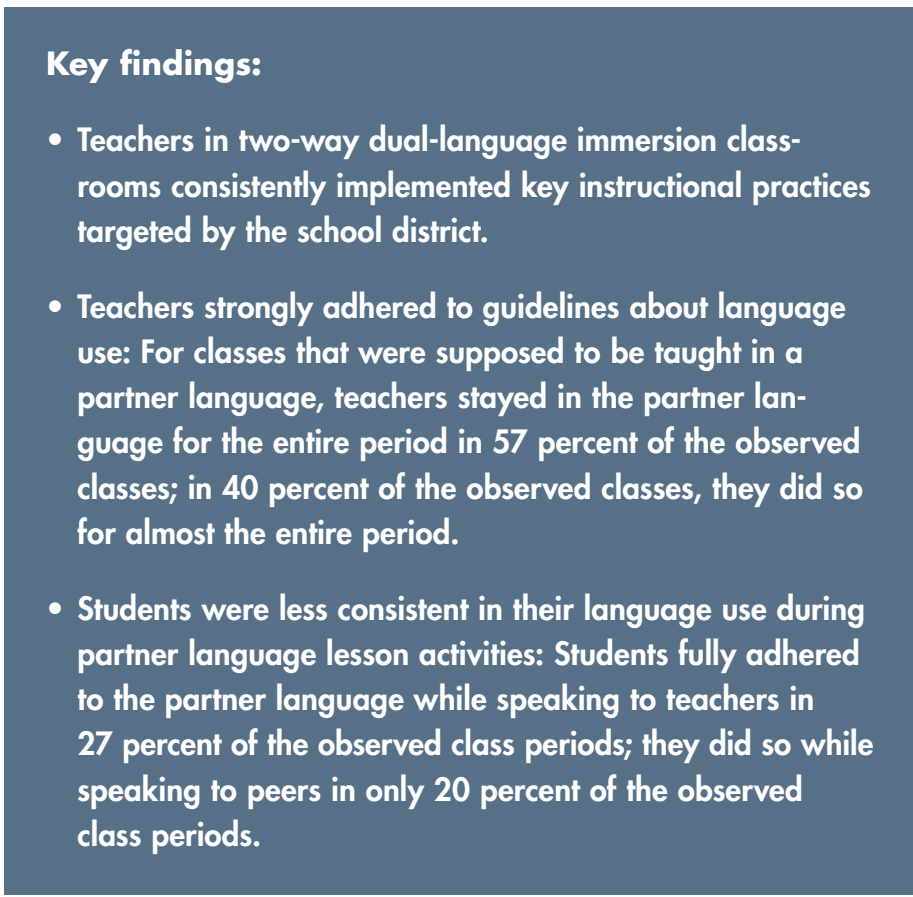

that language (i.e., adherence to the model). This research brief summarizes key findings from the observation data and offers a descriptive view of classroom practices in two-way programs in the district.

\section{Teachers Consistently Implemented Instructional Practices Targeted by the District}

In the first wave of data collection, which spanned grades $\mathrm{K}$ through 12, researchers focused on the instructional practices used by teachers as a way to gauge the quality of delivery. Because these practices can be applied in instruction in all languages, including English, the researchers were able to compare findings across different types of classes: those taught in the partner languages and those taught in English, either as part of the two-way dual-language immersion programs or as part of a traditional English-only program. Overall, teachers in all the observed classes consistently implemented 14 instructional practices (e.g., lesson preparation, learning strategies, lesson delivery) targeted by the district. Use of these practices was slightly more evident among 
teachers of partner language classes, but the difference was not statistically significant. These findings not only reflect well on the quality of delivery and the consistency of instruction in these two-way dual-language immersion programs, but they also suggest that any academic benefits of two-way dual-language immersion are likely to accrue through the acquisition and use of two languages rather than through systematic differences in teaching practices.

\section{Teachers Stayed in the Partner Languages to a Greater Extent Than Did Students During Lessons}

In the second wave of data collection, which included classrooms from grades $1,3,5,6$, and 7 , researchers observed the use of partner languages by teachers and students during partner language class periods as a way of gauging adherence to the two-way language model. In 57 percent of the observed class periods, teachers used the partner language throughout the entire period, and in 40 percent of classes, teachers did so for almost the entire period (90-99 percent of the time). Students' use of partner languages was more varied: In 27 percent of the observed class periods, students fully adhered to the partner language when speaking to teachers as part of the lesson activities, while in 67 percent of classes, students did so for almost the entire period (90-99 percent of the time).

When speaking to each other as part of lesson activities, students' use of the partner language was more limited: In just 20 percent of the observed class periods, students spoke exclusively in the partner language when interacting with a peer for lesson activities, and in 43 percent of the classes, students did so between 80 and 99 percent of the time. Translanguaging - the complex practices that emerging bilinguals engage in as they communicate in multiple cultural and sociolinguistic contexts-may explain the greater variation in students' use of partner languages, though analysis of this factor was beyond the scope of the study.

\section{How Often Do Students Have the Opportunity to Speak or Write During Lessons?}

In addition to opportunities for listening and reading, which are receptive skills, opportunities for students to produce either oral or written work during lessons are essential for building language proficiency. To better understand the opportunities available to students in this study, researchers looked at the extent to which students were asked to speak and write in the partner languages in the observed class periods. In more than half of the classes observed (55 percent), students were asked to produce a substantive amount of spoken language-telling a story, explaining a process, or describing a sequence of events in four sentences or longer-and this was true across all grades. Opportunities for students to write during the observed class periods were generally shorter: In only about one-third of the classes were students prompted to write four sentences or more.

\section{Looking Ahead}

While there is substantial evidence of the benefits of two-way dual-language immersion, the success of any given duallanguage program is constrained by the fidelity of its implementation. Given the positive findings from this study with regard to quality of delivery and adherence to the model, it would seem that the programs in this district are well positioned to help close achievement gaps and foster greater academic success. Going forward, as the number of two-way dual-language immersion programs continues to increase, lessons learned from this study may inform educators and policymakers about ways to refine two-way dual-language immersion programs and their implementation. If the cognitive benefits of bilingualism accrue through the active use of two languages, as other research indicates, the findings here about opportunities for students to speak and write in a partner language reveal an important area of focus for program design, educational leadership, and professional development.

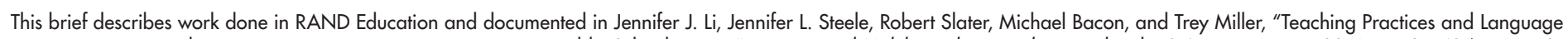

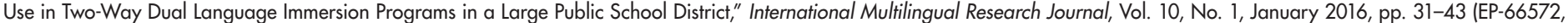

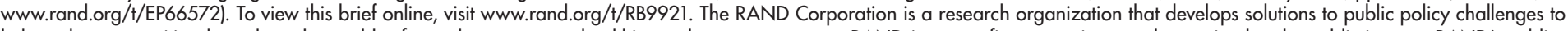

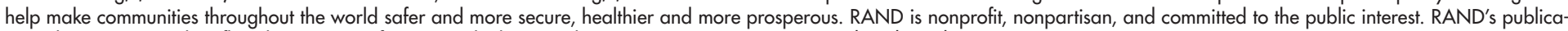
tions do not necessarily reflect the opinions of its research clients and sponsors. RAND ${ }^{\circledR}$ is a registered trademark. () RAND 2016

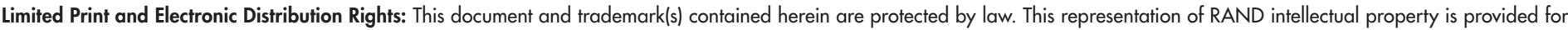

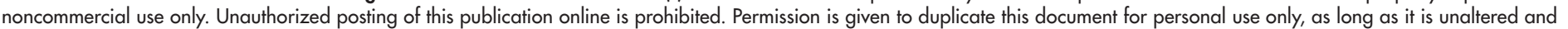

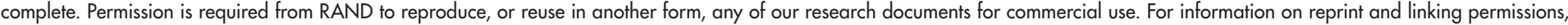
please visit www.rand.org/pubs/permissions.html. 